\section{Commentary: The downstream effects of thoracic multiorgan donation}

\author{
Sumner E. Kilmarx, AB, ${ }^{\mathrm{a}}$ and Leora B. Balsam, $\mathrm{MD}^{\mathrm{b}}$
}

The imbalance between thoracic organ supply and demand has led to significant need and urgency for expansion of the donor organ pool. Transplant programs have looked to extend donor organ utilization using novel means to rehabilitate organs both before and after procurement. ${ }^{1,2}$ For suitable donors, procurement of multiple organs is an invaluable way to increase the number of potential recipients who may benefit from a single donor. The technique of procurement of an isolated heart differs from the technique of procurement of both heart and lungs, and little comparative data have been published regarding the longand short-term outcomes after transplantation of a heart from an isolated heart (IH) donor versus a combined heart-lung (CHL) donor. Ram and colleagues ${ }^{3}$ describe their center's experience with $\mathrm{IH}$ versus CHL donors over a 20 -year period. Their findings are both remarkable and alarming, with a nearly 5 times higher incidence of primary graft dysfunction (PGD) in allografts from CHL donors compared with IH donors, independent of donor profiles.

Evaluating data from the United Network for Organ Sharing database from 1992 to 2006, Russo and colleagues ${ }^{4}$ were the first to report an association between CHL donors and primary graft failure using a set of hard definitions of death or retransplantion within 90 days. By contrast, Xia and colleagues ${ }^{5}$ did not find a significant difference in survival between heart transplant recipients of $\mathrm{IH}$ and CHL donor organs in the United Network for Organ Sharing

From the ${ }^{\mathrm{a} U n i v e r s i t y ~ o f ~ M a s s a c h u s e t t s ~ M e d i c a l ~ S c h o o l, ~ W o r c e s t e r, ~ M a s s ; ~ a n d ~}{ }^{\mathrm{b}}$ Division of Cardiac Surgery, UMass Memorial Medical Center, Worcester, Mass.

Disclosures: The authors reported no conflicts of interest.

The Journal policy requires editors and reviewers to disclose conflicts of interest and to decline handling or reviewing manuscripts for which they may have a conflict of interest. The editors and reviewers of this article have no conflicts of interest.

Received for publication Feb 10, 2021; revisions received Feb 10, 2021; accepted for publication Feb 11, 2021; available ahead of print Feb 19, 2021.

Address for reprints: Leora B. Balsam, MD, Division of Cardiac Surgery, UMass Memorial Medical Center, University Campus, 55 Lake Ave N, Worcester, MA 01655 (E-mail: leora.balsam@umassmemorial.org).

J Thorac Cardiovasc Surg 2023;165:196-7

$0022-5223 / \$ 36.00$

Copyright (c) 2021 by The American Association for Thoracic Surgery

https://doi.org/10.1016/j.jtcvs.2021.02.038

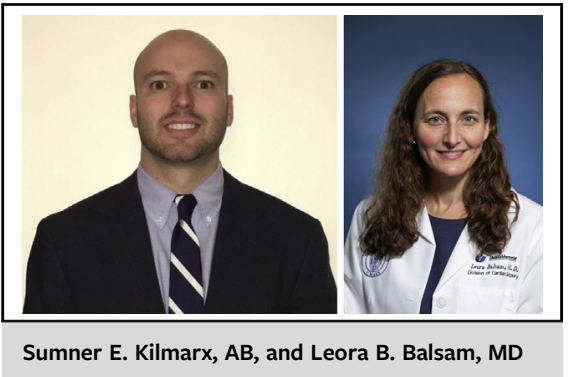

CENTRAL MESSAGE

A new study demonstrates

higher incidence of primary graft dysfunction in recipients of heart transplants from combined heart and lung donors versus isolated

heart donors.

dataset from 1998 to 2012. The authors propose that the discordance with the findings of Russo and colleagues ${ }^{4}$ was attributable to differences in donor and recipient selection and perioperative management in the later era, because the 2 datasets only partially overlapped. Ram and colleagues, ${ }^{3}$ study offers an important extension into an area that was not explored in either of these 2 studies: The incidence of PGD as defined by the International Society for Heart and Lung Transplantation Consensus Group in 2014. ${ }^{6}$

The pragmatism of multiorgan procurement, including CHL procurement, must be re-evaluated if recipient outcomes are not the same for IH and CHL donors. One obvious question is why does CHL donation increase the risk of PGD compared with IH donation. The authors hypothesize that technical factors during CHL explantation may contribute to development of PGD in the recipient of the heart. Each step in the CHL procurement therefore represents a leverage point where technique can be modified. Research in experimental animal models may be useful, as well as carefully controlled observational studies designed to identify intraoperative techniques that modify the risk of PGD with IH versus CHL donation.

Modern transplant programs must find a balance and safely transplant organs at a volume large enough to serve their populations. Nevertheless, the current study seeks to highlight a concerning trend in heart transplantation; namely, that programs may be overreaching and attempting to transplant too many organs from the same donor, resulting in higher PGD rates. 


\section{References}

1. Bakhtiyar SS, Godfrey EL, Ahmed S, Lamba H, Morgan J, Loor G, et al. Survival on the heart transplant waiting list. JAMA Cardiol. 2020;5: 1227-35.

2. Hsich EM. Matching the market for heart transplantation. Circ Heart Fail. 2016;9: e002679.

3. Ram E, Lavee J, Kassif Y, Peysakhovich Y, Sternik L, Segev A, et al. Primary heart dysfunction is greater with combined heart and lung compared with isolated heart procurement. J Thorac Cardiovasc Surg. 2023;165:186-95.e4.
4. Russo MJ, Iribarne A, Hong KN, Ramlawi B, Chen JM, Takayama H, et al. Factors associated with primary graft failure after heart transplantation. Transplantation. 2010;90:444-50.

5. Xia Y, Friedmann P, Bello R, Goldstein D, D’Alessandro D. Does lung donation by heart donors have an impact on survival in heart transplant recipients? Am J Transplant. 2017;17:506-11.

6. Kobashigawa J, Zuckermann A, Macdonald P, Leprince P, Esmailian F, Luu M et al. Report from a consensus conference on primary graft dysfunction after cardiac transplantation. J Heart Lung Transplant. 2014;33:327-40.
See Article page 186.

\section{Commentary: Combined heart-lung procurement: Avoiding the bottleneck effect}

\author{
Edward Buratto, MBBS, PhD, FRACS, ${ }^{\mathrm{a}, \mathrm{b}, \mathrm{c}}$ and \\ Igor E. Konstantinov, MD, PhD, FRACS ${ }^{a, b, c, d}$
}

Although primary graft dysfunction (PGD) is uncommon after cardiac transplantation, it remains the most common cause of early mortality. ${ }^{1}$ Transplantation services balance the need for organs with the additional risk of PGD when using marginal donors. Retrieving multiple organs from a single donor is a simple way to maximize organ availability; however, whether this carries additional risks is not entirely clear. Owing to an ongoing donor shortage worldwide, new techniques have been developed in an attempt to expand the donor pool, such as donation after cardiovascular death and ex vivo perfusion. ${ }^{2,3}$

The very interesting and important article by Ram and colleagues ${ }^{4}$ published in this issue of the Journal demonstrates that combined heart and lung (CHL) procurement dramatically increases the risk for PGD following heart

\footnotetext{
From the ${ }^{a}$ Department of Cardiac Surgery, Royal Children's Hospital, Melbourne; ${ }^{\mathrm{b}}$ Department of Paediatrics, University of Melbourne, Melbourne; ${ }^{\mathrm{c}}$ Heart Research Group, Murdoch Children's Research Institute, Melbourne; and the ${ }^{\mathrm{d}}$ Melbourne Centre for Cardiovascular Genomics and Regenerative Medicine, Melbourne, Australia.

Disclosures: The authors reported no conflicts of interest.

The Journal policy requires editors and reviewers to disclose conflicts of interest and to decline handling or reviewing manuscripts for which they may have a conflict of interest. The editors and reviewers of this article have no conflicts of interest.

Received for publication Feb 16, 2021; revisions received Feb 16, 2021; accepted for publication Feb 17, 2021; available ahead of print Feb 23, 2021.

Address for reprints: Igor E. Konstantinov, MD, PhD, FRACS, Royal Children's Hospital, Flemington Rd, Parkville 3052, Australia (E-mail: igor.konstantinov@rch. org.au).

J Thorac Cardiovasc Surg 2023;165:197-8

$0022-5223 / \$ 36.00$

Crown Copyright $(\subset) 2021$ Published by Elsevier Inc. on behalf of The American Association for Thoracic Surgery

https://doi.org/10.1016/j.jtcvs.2021.02.055
}

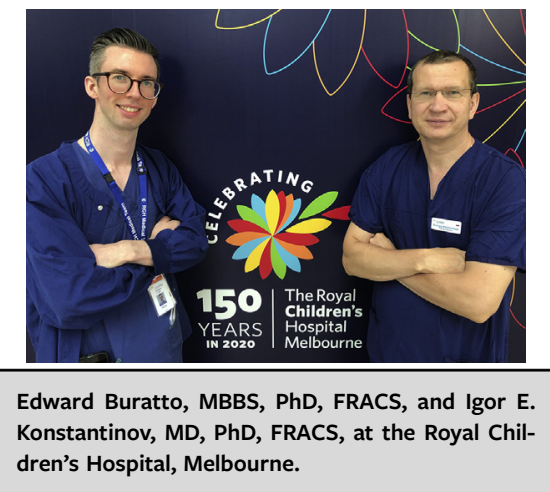

CENTRAL MESSAGE

The importance of left ventricular decompression cannot be overemphasized, particularly during combined procurement of the heart and the lungs.

transplantation compared with isolated heart (IH) procurement. A multivariable analysis confirmed that CHL was independently associated with an increased risk of PGD. Interestingly, although there was a somewhat longer ischemic time in the CHL group, the absolute difference was just over 15 minutes, and the mean ischemia time was well below the threshold of 240 minutes, which previously has been demonstrated to confer higher risk.

Why then should there be increased PGD, when the ischemia time is only marginally longer? Perhaps the additional ischemia time may indeed contribute to some degree. Although the impact of somewhat marginally prolonged ischemia time or amiodarone use was surprisingly unclear, the most striking feature was the fact that, compared with $1 \mathrm{~L}$ for $\mathrm{IH}$ procurement (Figure 1, $A$ ), the combined infused volume of cardioplegia and pneumoplegia was $6 \mathrm{~L}$ for $\mathrm{CHL}$ procurement (Figure 1, B). In the CHL procurement group, the initial infusion of $1 \mathrm{~L}$ of cardioplegic solution was 